\title{
Unexpected Nephrotoxicity in Male Ablactated Rats Induced by Cordyceps militaris: The Involvement of Oxidative Changes
}

\author{
Xiaowen Zhou and Yi Yao \\ Department of Pharmacy, Jiangsu Province Hospital of Traditional Chinese Medicine, Nanjing, Jiangsu 210036, China \\ Correspondence should be addressed to Yi Yao; wpaasj@126.com
}

Received 29 October 2012; Revised 8 January 2013; Accepted 16 January 2013

Academic Editor: Wagner Vilegas

Copyright (c) 2013 X. Zhou and Y. Yao. This is an open access article distributed under the Creative Commons Attribution License, which permits unrestricted use, distribution, and reproduction in any medium, provided the original work is properly cited.

Recently, many nutraceutical products containing the powdered or extracted parts of $C$. militaris have become available for health care. Due to the increased morbidity and mortality, poisonings associated with the use of herbs have raised the universal attention. Herein, we carried out the 28-day repeated toxicity test in male and female ablactated rats (three weeks old) given C. militaris powder orally at 0 (control), 1,2, and $3 \mathrm{~g} / \mathrm{kg}$ per day. Noticeable increments of serum aspartate and alanine aminotransferase (ALT and AST) levels were observed for both sexes, suggestive of weak hepatic toxicity. Nephrotoxicity characterized by tubular epithelium degeneration and necrosis was observed at the high dose, and the male rats were more susceptible to renal toxicity than female rats. In addition, the genes and protein expressions of novel markers of kidney toxicity, such as kidney injury molecule-1 (KIM-1) were enlarged in the renal cortex and the urine. Moreover, C. militaris treatment significantly decreased superoxide dismutase (SOD), catalase (CAT), and glutathione peroxidase (GPx) activities. However, the ratio of glutathione oxidized form (GSSG)/glutathione reduced form $(\mathrm{GSH})$ was increased by $C$. militaris treatment. We conclude that dietary contamination with C. militaris may have renal toxicity potentials, at least in part by causing oxidative damage to the kidney.

\section{Introduction}

The Ascomycete genus Cordyceps includes over 500 species that are pathogens of arthropods. Cordyceps species, such as $\mathrm{CCM}$ and $C$. sinensis, are highly prized in traditional Chinese medicines, and they are also increasingly being studied and used in the West [1]. CCM extract, polysaccharides, and cordycepin have exhibited immunostimulatory and antitumor effects [2-4], and two dietary supplements related to cultured Cordyceps have been approved by the State Food and Drug Administration of China since $2002[5,6]$.

Herbal plants used in therapeutics or as dietary supplements date back beyond the recorded history. Conceptually, herbs are usually considered to be nontoxic by the general public due to their natural origin. Even though the expected medical effect is not achieved, their excessive intake is not regarded to be dangerous by the general public. However, renal pathology of plant medicines has emerged [7-9]. Considering the complexity of herbals, it is now necessary to evaluate their safety before the clinical use. CCM has been used in daily supplement, especially for the teenagers and the aged. Since children may be more sensitive than adults when given toxicant exposure [10], we performed a 28-day repeated toxicity study to investigate the toxicity of CCM on young ablactated rats, and obvious nephrotoxicity was unexpectedly found.

\section{Materials and Methods}

2.1. Animals and Treatments. Eighty-three-week-old SD rats ( 40 males and 40 females) weighing $80-90 \mathrm{~g}$ obtained from SLEK Lab Animal Center (Shanghai, China) were used in this study and acclimatized for one week in the standard animal house prior to administration. Room temperature was maintained at $22 \pm 1^{\circ} \mathrm{C}$, relative humidity at $55 \pm 10 \%$, and a $12 \mathrm{~h}$ light/dark cycle. Distilled water and food for rats were available ad libitum.

CCM was purchased from XuanzuPharma. co., Ltd. (Xinjiang, China) after confirming the morphology under 
TABLE 1: Calibration curves and contents of nucleosides and nucleobases in CCM.

\begin{tabular}{lccc}
\hline & Calibration range $(\mu \mathrm{g} / \mathrm{mL})$ & $r^{2}$ & Contents, $\mathrm{mg} / \mathrm{g}$ \\
\hline Uridine & $4.8-240$ & 1 & 1.41 \\
Adenine & $0.72-36$ & 0.9999 & 0.05836 \\
Guanosine & $2.56-128$ & 1 & 0.45 \\
Adenosine & $2.976-148.8$ & 1 & 0.86 \\
Cordycepin & $6.8-340$ & 1 & 2.18 \\
\hline
\end{tabular}

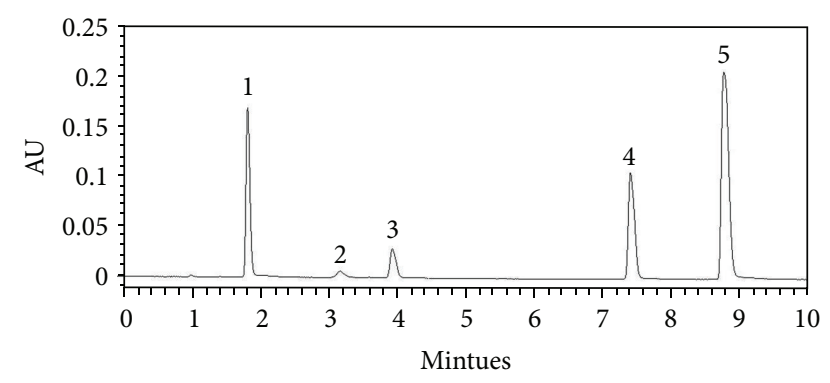

FIGURE 1: UPLC chromatogram of 5 standards. Peaks: 1, uridine; 2, adenine; 3 , guanosine; 4 , adenosine; 5 , cordycepin.

microscopy. CCM powder was made by an ultrafine pulverizer. Powders were stored in a desiccator to protect against light and moisture. After vigorous stirring, CCM suspension containing distilled water as vehicle was given to rats by a syringe via gastrointestinal tract in a minute. Rats were randomly divided into four groups, each consisting of 10 males and 10 females, and given 0 (control), 1, 2, and $3 \mathrm{~g} / \mathrm{kg}$ powered CCM once a day for 4 weeks. The animals were observed daily for clinical signs and mortality, and body weights were measured on the day of the administration (day 0 ) prior to treatment, $7,14,21$, and 28 days after the start of administration.

At the end, all animals were anesthetized with ether, weighed, and blood samples were collected from the abdominal aorta for haematology and biochemistry assays. Animals were then killed by exsanguination from the abdominal aorta. The tissues and organs, such as liver, spleen, kidneys, and testis (ovary), were fixed in $10 \%$ formalin for further histopathological diagnosis.

\subsection{UPLC Conditions for the Identifications of Nucleosides and} Nucleobases in CCM. Powered CCM samples were weighed into a volumetric flask. Approximately, $20 \mathrm{~mL}$ of water was added to the flask, which was subsequently sonicated for $1 \mathrm{~h}$. After centrifugation for 10 minutes at $4000 \times \mathrm{g}$, sample solution was dried at $60^{\circ} \mathrm{C}$, and the dried extract was dissolved in methanol-water $(50: 50, \mathrm{v} / \mathrm{v})$. The sample was finally filtrated through a $0.45 \mu \mathrm{M}$ membrane filter prior to the analysis.

The LC system used for the method development and method validation consisted of a Waters ACQUITY UPLC (Milford, MA, USA) with PDA Detector. The chromatographic separation was performed on Waters ACQUITY

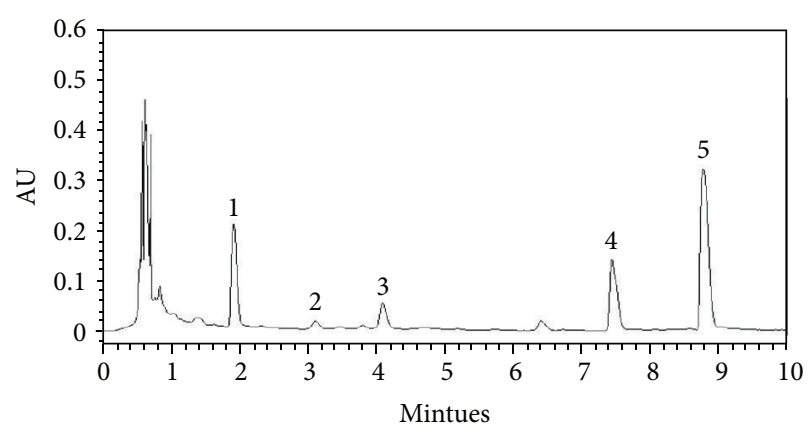

FIGURE 2: UPLC chromatograms of the water extracts from the fruiting bodies of $C$. militaris. Peaks: 1, uridine; 2, adenine; 3, guanosine; 4 , adenosine; 5 , cordycepin.

UPLC BEH C18 column $(100 \mathrm{~mm} \times 2.1 \mathrm{~mm}, 1.7 \mu \mathrm{m})$. Separation was carried out by linear gradient elution with methanol ( $2 \%$, in $0-2 \mathrm{~min} ; 2 \%-13 \%$, in $2-10 \mathrm{~min}$ ) and water (98\% in $0-$ $2 \mathrm{~min}$; $98 \%-87 \%$ in $2-10 \mathrm{~min}$ ) with a flow rate of $0.3 \mathrm{~mL} / \mathrm{min}$. The UV detection was operated at $260 \mathrm{~nm}$, and the injection volume was $20 \mu \mathrm{L}$. The external standard method was applied for the determinations. The identifications of nucleosides and nucleobases were attained by comparing their retention time and spectrum against known standards (Figures 1 and 2 and Table 1).

2.3. Haematology and Biochemistry. Red blood cell count (RBC), white blood cell count (WBC), hemoglobin concentration, and white blood cell differential count (neutrophils, lymphocytes, monocyte, eosinophil, and basophil) were conducted using automated hematology cell counter CELLDYN 3700 (Abbott Diagnostics, Santa Clara, CA, USA). Serum levels of aspartate aminotransferase (AST), alanine aminotransferase (ALT), total protein, albumin, blood urea nitrogen (BUN), creatinine, glucose, triglyceride, and total cholesterol (TC) were conducted using autoanalyzer (Type 7020, Hitachi, Japan). In addition, chloride (Cl), sodium (Na), and potassium $(\mathrm{K})$ were measured using an ion autoanalyzer (Dri-Chem 800, Fuji, Japan).

2.4. Histopathological Examination. All histopathological tests were performed using standard laboratory procedures. The tissues were processed and trimmed, embedded in paraffin, sectioned to a thickness of $4-6 \mu \mathrm{m}$, and placed onto glass slides. After stained with hematoxylin and eosin, the slides were observed, and the photos were taken using binocular Olympus DX45 microscope. 
TABLE 2: Sequences of the primers.

\begin{tabular}{lccc}
\hline Gene & GenBank number & Forward & Reverse \\
\hline Beta-Actin & V01217 & TGACCGAGCGTGGCTACAG & GGGCAACATAGCACAGCTTCT \\
KIM-1 & NM-173149 & TGGCACTGTGACATCCTCAGA & GCAACGGACATGCCAACATA \\
\hline
\end{tabular}

TABLE 3: Weekly body weight (g) of rats treated with CCM for 28 days.

\begin{tabular}{|c|c|c|c|c|c|}
\hline \multirow{2}{*}{ Treatment $(\mathrm{g} / \mathrm{kg})$} & \multicolumn{5}{|c|}{ Days } \\
\hline & 0 & 7 & 14 & 21 & 28 \\
\hline \multicolumn{6}{|c|}{ Male rats } \\
\hline 0 & $81.1 \pm 4.4$ & $147.1 \pm 8.6$ & $224.2 \pm 26.1$ & $290.2 \pm 26.1$ & $375.1 \pm 39.7$ \\
\hline 1 & $81.2 \pm 4.3$ & $142.7 \pm 9.2$ & $213.6 \pm 25.1$ & $277.3 \pm 20.2$ & $359.8 \pm 32.2$ \\
\hline 2 & $82.4 \pm 4.1$ & $139.5 \pm 10.5$ & $201.2 \pm 28.1$ & $253.4 \pm 26.3$ & $313.7 \pm 35.4$ \\
\hline 3 & $82.1 \pm 4.2$ & $133.2 \pm 7.2$ & $179.5 \pm 11.8$ & $248.5 \pm 21.4$ & $319.6 \pm 31.4$ \\
\hline \multicolumn{6}{|c|}{ Female rats } \\
\hline 0 & $80.1 \pm 4.4$ & $135.6 \pm 17.5$ & $187.4 \pm 10.2$ & $211.5 \pm 10.1$ & $247.2 \pm 25.1$ \\
\hline 1 & $80.2 \pm 4.2$ & $129.6 \pm 19.6$ & $174.4 \pm 10.3$ & $199.7 \pm 11.2$ & $237.6 \pm 24.2$ \\
\hline 2 & $80.8 \pm 4.2$ & $126.8 \pm 14.7$ & $172.6 \pm 16.6$ & $193.6 \pm 17.5$ & $217.5 \pm 28.3$ \\
\hline 3 & $80.3 \pm 4.1$ & $131.9 \pm 17.3$ & $171.6 \pm 16.7$ & $191.5 \pm 20.5$ & $224.5 \pm 24.4$ \\
\hline
\end{tabular}

Each value is expressed as mean $\pm \mathrm{SD}(n=10 /$ sex/dose $)$.

2.5. Real-Time RT-PCR. Kidney tissues from renal cortex were harvested and quickly submerged in TRIzol solution (KeyGen Biotech. Co., Ltd., Nanjing, China). Total RNAs were extracted by using an RNeasy Mini Kit (Qiagen, Hilden, Germany). RNA concentration was assessed spectrophotometrically by measuring the A260/A280 absorbance ratios. The PCR primers were designed with Primer Express software (Applied Biosystems, CA, USA) and listed in Table 2. The amplification protocol consisted of 10 minutes at $95^{\circ} \mathrm{C}$ and followed by 36 cycles of amplification $\left(95^{\circ} \mathrm{C}\right.$ for $10 \mathrm{~s}, 54^{\circ} \mathrm{C}$ for $5 \mathrm{~s}$, and $72^{\circ} \mathrm{C}$ for $15 \mathrm{~s}$ ). Subsequently, the reaction was stopped at $95^{\circ} \mathrm{C}$ for 2 minutes, cooled $\left(20^{\circ} \mathrm{C}\right.$ for 1 minutes), and melted $\left(70-94^{\circ} \mathrm{C}\right.$ with plate readings set at $\left.0.5^{\circ} \mathrm{C}\right)$ in an ABI 7300 real-time PCR system (Applied Biosystems) using the DNA-binding dye technique (SYBR Green). Differences in gene expression were calculated using cycle threshold (Ct) values, which were normalized against beta-actin of the same sample and expressed as relative transcript levels setting controls as $100 \%$.

2.6. Western Blot. Kidney tissues from the renal cortex were loaded, and $30 \mu \mathrm{g}$ of protein from the supernatants was then separated by $10 \%$ SDS polyacrylamide gel electrophoresis and transferred onto nitrocellulose membranes. After blocking with $10 \%$ nonfat milk for $1 \mathrm{~h}$ at room temperature, the membranes were washed three times with PBST and incubated with antibodies against kidney injury molecular1 (kIM-1) and GAPDH from Bioworld Biotech Co., Ltd. (Nanjing, China). Subsequently, membranes were incubated with peroxidase-conjugated secondary antibodies for $1 \mathrm{~h}$ at room temperature. Membranes were visualized with chemoluminescence reagents. Image pro plus (IPP) software for densitometry analysis is applied for the quantification of protein expressions.
2.7. KIM-1 Assay in Urine. KIM-1 protein level was detected in the urine using an ELISA kit and according to the manufacturer's instructions (R\&D Systems, Abingdon, UK). Urine was diluted per 10 or 100 to comply with the concentration intervals of the assay.

2.8. Oxidative Stress Markers in the Kidney. Tissues from the renal cortex were harvested, and superoxide dismutase (SOD) and catalase (CAT) activities were determined according to recently described methods [11]. Glutathione oxidized form (GSSG) and glutathione reduced form (GSH) levels were analyzed according to methods [12] with a fluorescence microscope. Glutathione reductase (GR) activity was assayed using GSSG as a substrate and measuring the disappearance of NADPH [13]. The measurement of glutathione peroxidase (GPx) activity was performed according to a method based on the monitoring of the oxidation of NADPH at $340 \mathrm{~nm}$. Glutathione S-transferase (GST) activity was examined as previously described [14].

2.9. Statistical Analyses. Data are presented as mean \pm SD. Statistical analysis between groups was made by variance analysis (ANOVA), followed by Duncan's multiple range test. $P<0.05$ was considered to be a significant difference. In addition, degrees of histopathological findings were subdivided into 4 degrees: $( \pm)$ very slight; $(+)$ slight; $(++)$ moderate; $(+++)$ severe.

\section{Result}

3.1. Mortalities and Changes of Body Weights. No mortalities were recorded in all three different dosages tested. In the main study, diarrhea occurred sporadically during the treatment period in some males at middle and high doses. 
TABLE 4: Organ-to-body weight ratios of rats treated with CCM for 28 days.

\begin{tabular}{lcccc}
\hline Treatment $(\mathrm{g} / \mathrm{kg})$ & Liver (\%) & Spleen $(\%)$ & Kidney $(\%)$ & Testis (\%) \\
\hline \multicolumn{5}{c}{ Male rats } \\
0 & $3.44 \pm 0.19$ & $0.25 \pm 0.03$ & $0.86 \pm 0.02$ & $0.88 \pm 0.07$ \\
1 & $3.39 \pm 0.19$ & $0.24 \pm 0.03$ & $0.89 \pm 0.07$ & $0.89 \pm 0.09$ \\
2 & $3.33 \pm 0.22$ & $0.24 \pm 0.02$ & $0.94 \pm 0.11$ & $1.03 \pm 0.09^{* *}$ \\
3 & $3.37 \pm 0.12$ & $0.24 \pm 0.02$ & $0.91 \pm 0.06^{*}$ & $1.04 \pm 0.09^{* *}$ \\
& & & \\
0 & $3.52 \pm 0.45$ & $0.23 \pm 0.04$ & $0.80 \pm 0.13$ & $0.06 \pm 0.01$ \\
1 & $3.46 \pm 0.34$ & $0.22 \pm 0.02$ & $0.84 \pm 0.11$ & $0.05 \pm 0.01$ \\
2 & $3.36 \pm 0.16$ & $0.22 \pm 0.04$ & $0.73 \pm 0.05$ & $0.06 \pm 0.01$ \\
3 & $3.55 \pm 0.17$ & $0.22 \pm 0.04$ & $0.77 \pm 0.06$ & $0.06 \pm 0.01$ \\
\hline
\end{tabular}

Each value is expressed as mean $\pm \mathrm{SD}(n=10 /$ sex/dose $)$.

${ }^{*} P<0.05 ;{ }^{* *} P<0.01$.

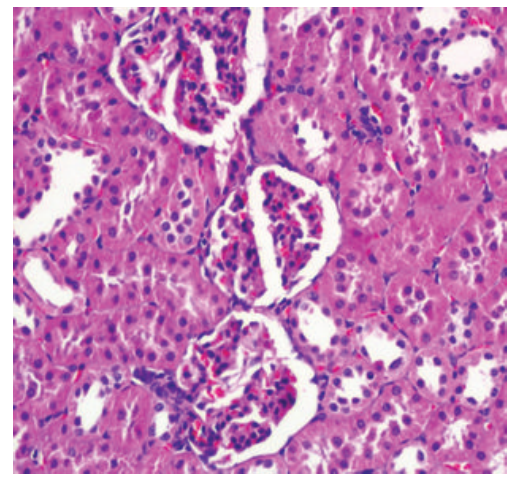

(a)

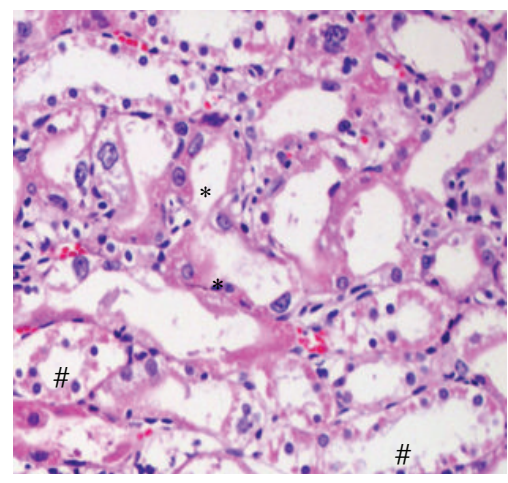

(d)

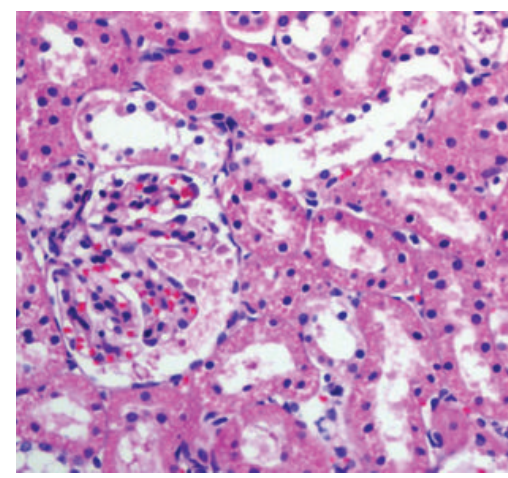

(b)

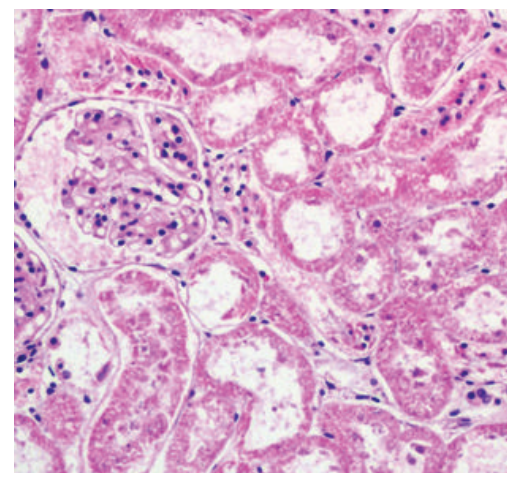

(e)

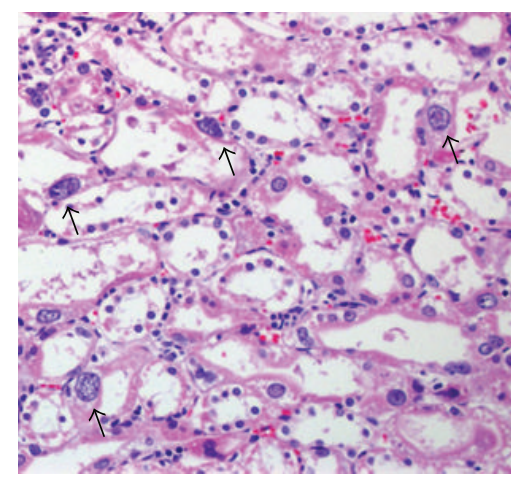

(c)

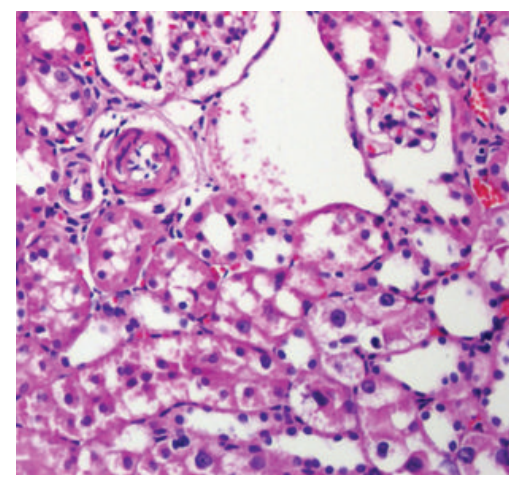

(f)

FIGURE 3: Micrographs showing histopathological changes in kidneys. (a) Normal glomeruli and renal tubules, the control group. (b) Proteinaceous effusion in the glomerular capsule as well as focal proteinaceous casts in the tubular lumina, male rats at $3 \mathrm{~g} / \mathrm{kg}$ group. (c) Arrows indicate larger cells with one more nucleolus, male rats at $3 \mathrm{~g} / \mathrm{kg}$ group. (d) Extensive necrosis and sloughing of proximal tubular epithelium. \# indicates necrotic debris, and * indicates tubular vacuolar degeneration, male rats at $3 \mathrm{~g} / \mathrm{kg}$ group. (e) Dilated tubular epithelium without evidence of nuclear detail, male rats at $3 \mathrm{~g} / \mathrm{kg}$ group. (f) Slight infiltration and moderate edema, female rats at $3 \mathrm{~g} / \mathrm{kg}$ group.

No alterations on body weight were observed as compared with the control group in all doses regardless of animal genders (Table 3).

3.2. Changes on the Organ-to-Body Weight Ratios and on the Clinical Indicators. After weighing the body and tissues, the coefficients of liver, kidneys, testis (ovary), and spleen to body weight were calculated as the ratio of tissues to body weight (Table 4). After exposure to $3 \mathrm{~g} / \mathrm{kg}$ dose, significant increases of kidney-to-body weight ratio $(P<0.05)$ and testis-to-body weight ratio $(P<0.01)$ were found.

No alterations were observed in triglyceride, glucose, albumin, and total protein levels between CCM-treated groups and the control group (Table 5), while rats at $3 \mathrm{~g} / \mathrm{kg}$ 
TABLE 5: Hematological values and biochemical parameters of rats treated with CCM for 28 days.

\begin{tabular}{|c|c|c|c|c|}
\hline \multirow{2}{*}{ Item } & \multicolumn{4}{|c|}{ Treatment (g/kg) } \\
\hline & 0 & 1 & 2 & 3 \\
\hline \multicolumn{5}{|c|}{ Male rats } \\
\hline $\mathrm{WBC}\left(\times 10^{9} / \mathrm{L}\right)$ & $7.1 \pm 1.5$ & $6.9 \pm 1.6$ & $6.3 \pm 1.1$ & $6.9 \pm 1.7$ \\
\hline $\mathrm{RBC}\left(\times 10^{12} / \mathrm{L}\right)$ & $7.1 \pm 1.3$ & $7.3 \pm 1.2$ & $7.3 \pm 1.4$ & $7.3 \pm 1.4$ \\
\hline Hemoglobin (g/L) & $149.2 \pm 15.1$ & $148.3 \pm 15.2$ & $147.4 \pm 19.1$ & $147.5 \pm 16.3$ \\
\hline Lymphocyte (\%) & $78.8 \pm 11.9$ & $78.5 \pm 12.5$ & $76.8 \pm 13.5$ & $78.9 \pm 12.5$ \\
\hline Neutrophil (\%) & $13.4 \pm 3.6$ & $14.1 \pm 3.5$ & $15.3 \pm 7.0$ & $14.9 \pm 3.9$ \\
\hline Monocyte (\%) & $6.7 \pm 2.3$ & $6.2 \pm 1.5$ & $6.8 \pm 2.0$ & $6.6 \pm 2.5$ \\
\hline Eosinophil (\%) & $0.7 \pm 0.4$ & $0.8 \pm 0.4$ & $0.7 \pm 0.5$ & $0.8 \pm 0.4$ \\
\hline Basophil (\%) & $0.4 \pm 0.2$ & $0.4 \pm 0.2$ & $0.4 \pm 0.2$ & $0.4 \pm 0.3$ \\
\hline $\operatorname{ALT}(\mathrm{U} / \mathrm{L})$ & $22 \pm 3$ & $22 \pm 3$ & $27 \pm 5^{*}$ & $29 \pm 5^{* *}$ \\
\hline AST (U/L) & $97 \pm 8$ & $109 \pm 23$ & $125 \pm 13^{* *}$ & $129 \pm 15^{* *}$ \\
\hline Totol protein $(\mathrm{g} / \mathrm{L})$ & $52.1 \pm 3.3$ & $52.3 \pm 4.6$ & $52.4 \pm 3.8$ & $55.1 \pm 3.7$ \\
\hline Albumin $(\mathrm{g} / \mathrm{L})$ & $30.0 \pm 0.9$ & $30.0 \pm 1.3$ & $30.5 \pm 0.9$ & $30.1 \pm 0.8$ \\
\hline BUN (mg/dL) & $11.9 \pm 2.2$ & $12.2 \pm 2.1$ & $12.1 \pm 3.3$ & $12.5 \pm 4.6$ \\
\hline Creatinine (mg/dL) & $0.55 \pm 0.11$ & $0.54 \pm 0.16$ & $0.56 \pm 0.17$ & $0.54 \pm 0.15$ \\
\hline $\mathrm{TC}(\mathrm{mmol} / \mathrm{L})$ & $1.79 \pm 0.30$ & $1.66 \pm 0.20$ & $1.56 \pm 0.17$ & $1.43 \pm 0.29^{*}$ \\
\hline Triglyceride (mmol/L) & $0.72 \pm 0.33$ & $0.65 \pm 0.19$ & $0.50 \pm 0.07$ & $0.52 \pm 0.17$ \\
\hline Glucose (mmol/L) & $6.02 \pm 0.40$ & $6.09 \pm 0.89$ & $5.91 \pm 0.98$ & $5.93 \pm 0.78$ \\
\hline $\mathrm{Na}(\mathrm{mmol} / \mathrm{L})$ & $137 \pm 1$ & $138 \pm 1$ & $138 \pm 2$ & $139 \pm 2$ \\
\hline $\mathrm{K}(\mathrm{mmol} / \mathrm{L})$ & $5.10 \pm 0.65$ & $5.22 \pm 0.56$ & $5.15 \pm 0.78$ & $5.14 \pm 0.54$ \\
\hline $\mathrm{Cl}(\mathrm{mmol} / \mathrm{L})$ & $98 \pm 1$ & $97 \pm 1$ & $97 \pm 2$ & $98 \pm 3$ \\
\hline \multicolumn{5}{|c|}{ Female rats } \\
\hline $\mathrm{WBC}\left(\times 10^{9} / \mathrm{L}\right)$ & $7.5 \pm 1.4$ & $5.9 \pm 1.1$ & $6.0 \pm 1.1$ & $6.2 \pm 1.4$ \\
\hline $\mathrm{RBC}\left(\times 10^{12} / \mathrm{L}\right)$ & $7.4 \pm 0.3$ & $7.7 \pm 0.4$ & $7.7 \pm 0.4$ & $7.5 \pm 0.5$ \\
\hline Hemoglobin (g/L) & $151.2 \pm 6.1$ & $153.3 \pm 10.4$ & $151.5 \pm 6.1$ & $150.4 \pm 6.2$ \\
\hline Lymphocyte (\%) & $79.1 \pm 14.0$ & $77.5 \pm 11.2$ & $80.1 \pm 14.9$ & $78.8 \pm 13.7$ \\
\hline Neutrophil (\%) & $13.9 \pm 3.5$ & $14.0 \pm 5.7$ & $13.3 \pm 4.9$ & $13.3 \pm 3.5$ \\
\hline Monocyte (\%) & $5.7 \pm 1.7$ & $7.6 \pm 3.3$ & $5.9 \pm 1.4$ & $6.8 \pm 2.8$ \\
\hline Eosinophil (\%) & $0.8 \pm 0.7$ & $0.5 \pm 0.5$ & $0.4 \pm 0.4$ & $0.8 \pm 0.5$ \\
\hline Basophil (\%) & $0.4 \pm 0.2$ & $0.3 \pm 0.2$ & $0.3 \pm 0.2$ & $0.4 \pm 0.2$ \\
\hline $\operatorname{ALT}(\mathrm{U} / \mathrm{L})$ & $20 \pm 3$ & $22 \pm 3$ & $25 \pm 4^{*}$ & $28 \pm 4^{* *}$ \\
\hline AST (U/L) & $92 \pm 9$ & $98 \pm 11$ & $112 \pm 14^{* *}$ & $126 \pm 12^{* *}$ \\
\hline Totol protein $(\mathrm{g} / \mathrm{L})$ & $56.0 \pm 4.6$ & $56.9 \pm 2.8$ & $56.8 \pm 2.1$ & $53.0 \pm 1.9$ \\
\hline Albumin $(\mathrm{g} / \mathrm{L})$ & $34.4 \pm 2.5$ & $33.2 \pm 1.5$ & $33.1 \pm 0.9$ & $30.6 \pm 0.9$ \\
\hline BUN (mg/dL) & $12.5 \pm 2.1$ & $12.8 \pm 3.4$ & $13.6 \pm 3.9$ & $13.2 \pm 3.1$ \\
\hline Creatinine (mg/dL) & $0.57 \pm 0.05$ & $0.60 \pm 0.11$ & $0.63 \pm 0.09$ & $0.60 \pm 0.11$ \\
\hline $\mathrm{TC}(\mathrm{mmol} / \mathrm{L})$ & $1.97 \pm 0.23$ & $1.77 \pm 0.26$ & $1.89 \pm 0.32$ & $1.56 \pm 0.21^{*}$ \\
\hline Triglyceride (mmol/L) & $0.67 \pm 0.37$ & $0.59 \pm 0.36$ & $0.42 \pm 0.12$ & $0.50 \pm 0.25$ \\
\hline Glucose (mmol/L) & $5.98 \pm 0.99$ & $5.88 \pm 1.00$ & $5.72 \pm 0.70$ & $5.80 \pm 0.87$ \\
\hline $\mathrm{Na}(\mathrm{mmol} / \mathrm{L})$ & $143 \pm 1$ & $142 \pm 2$ & $143 \pm 1$ & $139 \pm 1$ \\
\hline $\mathrm{K}(\mathrm{mmol} / \mathrm{L})$ & $5.65 \pm 0.72$ & $5.63 \pm 0.83$ & $5.62 \pm 0.51$ & $5.60 \pm 0.49$ \\
\hline $\mathrm{Cl}(\mathrm{mmol} / \mathrm{L})$ & $100 \pm 2$ & $98 \pm 2$ & $98 \pm 2$ & $96 \pm 2$ \\
\hline
\end{tabular}

Each value is expressed as mean \pm SD ( $n=10 /$ sex/dose). RBC: red blood cell count; WBC: white blood cell count; AST: aspartate aminotransferase; ALT: alanine aminotransferase; BUN: blood urea nitrogen; TC: total cholesterol; Cl: chloride; Na: sodium; K: potassium.

${ }^{*} P<0.05 ;{ }^{* *} P<0.01$.

dosage group had decreased total cholesterol serum concentrations in both genders $(P<0.05)$. Both $2 \mathrm{~g} / \mathrm{kg}$ and $3 \mathrm{~g} / \mathrm{kg}$ groups showed higher ALT and AST levels regardless of animal genders, respectively.
3.3. Histopathological Findings. Histological examination of haematoxylin and eosin stained sections displayed significant renal pathology at high-dose group compared to the control group (Figure 3(a)), whereas other tissues (brain, heart, liver, 


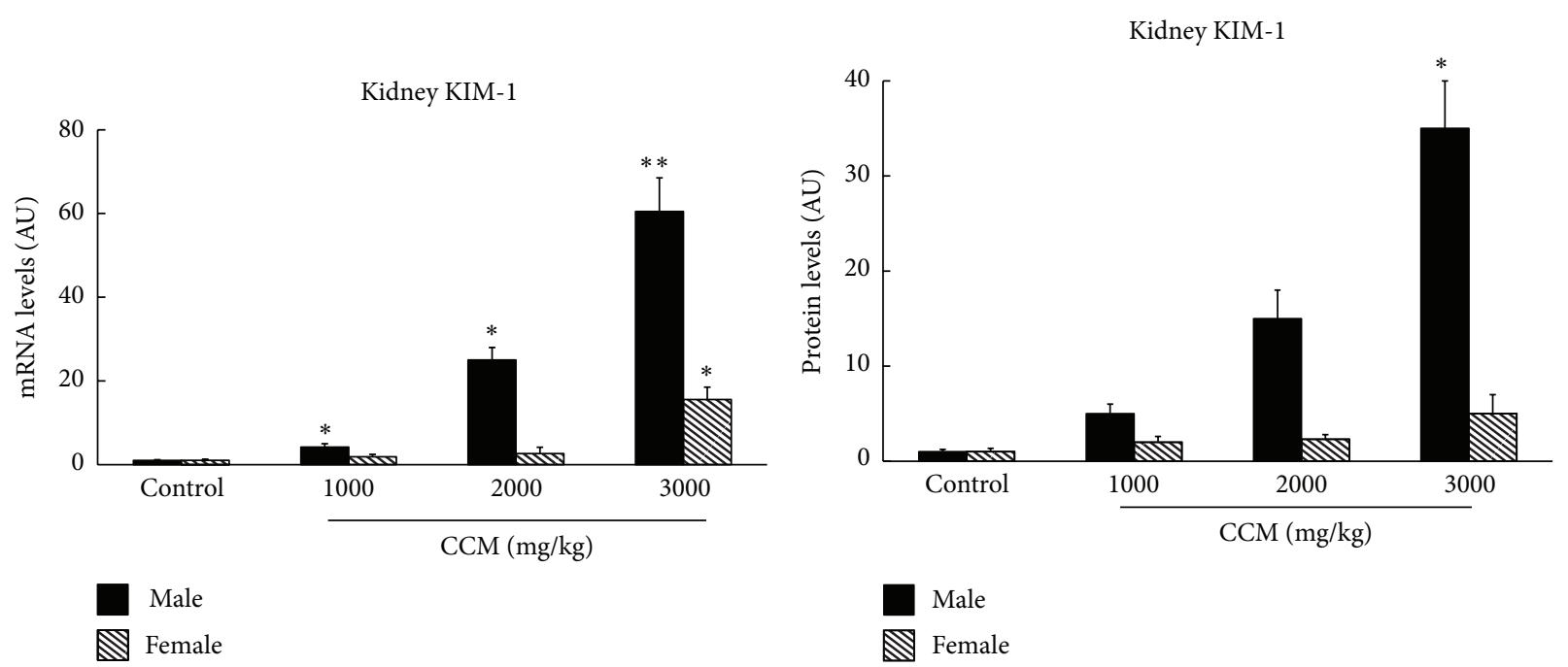

(a)

Kidney KIM-1

(b)

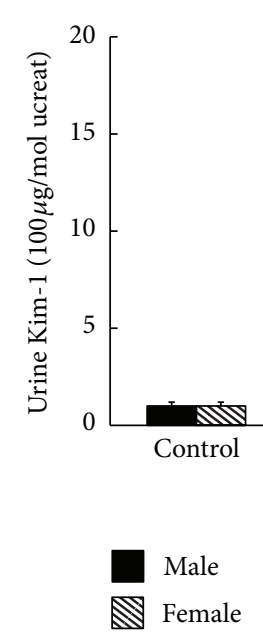

(c)

FIGURE 4: KIM-1 gene expression (a) and protein level (b) in renal cortex of kidney and in urine (c) from rats orally given CCM for 28 days. Urines were collected for $24 \mathrm{~h}$ via metabolism cage and blood and kidney were collected. The cortex section of kidney was separated $(n=10$ for each group). The results are expressed as a ratio to the housekeeping gene mRNA levels, AU, arbitrary unit. ${ }^{*} P<0.05$.

pancreas, testis, ovary, lung, and spleen) were unaffected. There was a lot of eosin stained proteinaceous effusion in the glomerular capsule as well as focal proteinaceous casts in the tubular lumina (Figure 3(b)). Besides, some renal tubular epithelial cells were significantly larger sized and characterized with one more nucleolus (Figure 3(c)). Cells have sloughed from the basement membranes in some tubules, and necrotic debris has accumulated in the lumina. Variably sized and clear vacuoles were also detectable in the cytoplasm (Figure 3(d)). Administration at $3 \mathrm{~g} / \mathrm{kg}$ dose also induced necrosis of the pars convoluta, without evidence of nuclear detail (Figure 3(e)). The above-mentioned lesions were significantly attenuated in the female compared with the male, which means the nephrotoxicity was specific for the male (Figure 3(f) and Table 6).

3.4. KIM-1 Expression. CCM treatment caused significant up-regulation of kIM-1 gene and protein expression in the renal cortex and the urine (Figure 4). In details, kIM-1 mRNA levels in male rats were increased of 4-, 20-, or 61fold versus control by 1,2 , and $3 \mathrm{~g} / \mathrm{kg}$ treatment, respectively (Figure 4(a)), whereas kIM-1 mRNA increment in female rats was only observed at the high dose (16-fold versus control). The protein level of kIM-1 also amplified significantly in male rats (35-fold) (Figure 4(b)). The same tendency, although not statistically significant, was noted in urine kIM-1 expression in male rats (Figure 4(c)). Nevertheless, no significant difference of kIM-1 protein level was observed in both renal cortex and urine for the female rats (Figures 4(b) and 4(c)).

3.5. Antioxidant Enzyme Activities. Antioxidant enzyme activities (SOD, CAT, GR, GPx, and GST) and the oxidative stress maker GSSG/GSH ratio in renal cortex of ablactated rats given CCM are summarized in Table 7 . For male rats, a significant reduction in SOD, CAT and GPx activities in $3 \mathrm{~g} / \mathrm{kg}$ group was observed compared with the control group. 
TABLE 6: Incidence of renal histopathological findings of rats treated orally with CCM for 28 days from weaning.

\begin{tabular}{|c|c|c|c|c|c|c|c|c|c|}
\hline \multirow{3}{*}{ Findings } & \multirow{3}{*}{ Grade } & \multicolumn{8}{|c|}{ Treatment (g/kg) } \\
\hline & & \multicolumn{4}{|c|}{ Male rats } & \multicolumn{4}{|c|}{ Female rats } \\
\hline & & 0 & 1 & 2 & 3 & 0 & 1 & 2 & 3 \\
\hline \multirow[t]{2}{*}{ Glomerular exudate } & ++ & 0 & 0 & 1 & 3 & 0 & 0 & 0 & 0 \\
\hline & +++ & 0 & 0 & 3 & 7 & 0 & 0 & 0 & 0 \\
\hline \multirow{4}{*}{ Degeneration, tubular epithelium } & \pm & 1 & 0 & 0 & 0 & 0 & 0 & 0 & 1 \\
\hline & + & 2 & 0 & 0 & 0 & 1 & 0 & 0 & 1 \\
\hline & ++ & 0 & 0 & 2 & 5 & 0 & 0 & 0 & 1 \\
\hline & +++ & 0 & 0 & 2 & 4 & 0 & 0 & 0 & 0 \\
\hline \multirow[t]{3}{*}{ Necrosis, tubular epithelium } & + & 0 & 0 & 0 & 2 & 0 & 0 & 0 & 0 \\
\hline & ++ & 0 & 0 & 1 & 3 & 0 & 0 & 0 & 0 \\
\hline & +++ & 0 & 0 & 0 & 1 & 0 & 0 & 0 & 0 \\
\hline \multirow[t]{2}{*}{ Nuclear condensation, tubular epithelium } & + & 0 & 0 & 0 & 4 & 0 & 0 & 0 & 0 \\
\hline & ++ & 0 & 0 & 3 & 6 & 0 & 0 & 0 & 0 \\
\hline \multirow[t]{2}{*}{ Inflammation, interstitial } & \pm & 0 & 0 & 0 & 0 & 0 & 0 & 0 & 1 \\
\hline & + & 0 & 0 & 0 & 1 & 0 & 0 & 0 & 0 \\
\hline
\end{tabular}

$( \pm)$ : very slight; (+): slight; (++): moderate; $(+++)$ : severe.

TABLE 7: Effects of CCM exposure on antioxidant enzyme activities in kidneys of ablactated rats.

\begin{tabular}{|c|c|c|c|c|}
\hline \multirow{2}{*}{ Item } & \multicolumn{4}{|c|}{ Treatment $(\mathrm{g} / \mathrm{kg})$} \\
\hline & 0 & 1 & 2 & 3 \\
\hline \multicolumn{5}{|c|}{ Male rats } \\
\hline SOD (U/mg protein) & $29.4 \pm 6.4$ & $29.3 \pm 5.2$ & $26.9 \pm 6.2$ & $23.2 \pm 5.5^{*}$ \\
\hline $\mathrm{CAT}(\mu \mathrm{mol} / \mathrm{min} / \mathrm{mg}$ protein $)$ & $154.1 \pm 21.5$ & $150.2 \pm 23.7$ & $149.3 \pm 24.7$ & $126.1 \pm 22.9^{*}$ \\
\hline GR (mU/mg protein) & $552.1 \pm 101.3$ & $550.3 \pm 110.6$ & $525.4 \pm 112.8$ & $520.2 \pm 119.9$ \\
\hline GPx (mU/mg protein) & $923.6 \pm 213.5$ & $880.5 \pm 187.9$ & $856.3 \pm 198.3$ & $840.9 \pm 201.5^{*}$ \\
\hline GST (mU/mg protein) & $0.68 \pm 0.15$ & $0.68 \pm 0.16$ & $0.69 \pm 0.17$ & $0.65 \pm 0.18$ \\
\hline GSSG/GSH ratio & $0.65 \pm 0.11$ & $0.64 \pm 0.16$ & $0.78 \pm 0.12$ & $0.97 \pm 0.25^{*}$ \\
\hline \multicolumn{5}{|c|}{ Female rats } \\
\hline SOD (U/mg protein) & $35.2 \pm 7.1$ & $34.1 \pm 6.4$ & $31.2 \pm 6.5$ & $28.7 \pm 4.4^{*}$ \\
\hline $\mathrm{CAT}(\mu \mathrm{mol} / \mathrm{min} / \mathrm{mg}$ protein $)$ & $143.2 \pm 18.3$ & $145.2 \pm 21.8$ & $140.5 \pm 23.5$ & $136.3 \pm 21.3$ \\
\hline GR (mU/mg protein) & $514.5 \pm 121.7$ & $502.2 \pm 104.9$ & $497.3 \pm 112.2$ & $505.3 \pm 124.5$ \\
\hline GPx (mU/mg protein) & $822.5 \pm 194.4$ & $823.4 \pm 199.2$ & $801.5 \pm 195.7$ & $811.8 \pm 215.7$ \\
\hline GST (mU/mg protein) & $0.54 \pm 0.11$ & $0.55 \pm 0.12$ & $0.58 \pm 0.13$ & $0.54 \pm 0.12$ \\
\hline GSSG/GSH ratio & $0.71 \pm 0.10$ & $0.73 \pm 0.15$ & $0.79 \pm 0.17$ & $0.96 \pm 0.21^{*}$ \\
\hline
\end{tabular}

Each value is expressed as mean $\pm \mathrm{SD}(n=10 /$ sex/dose).

SOD: superoxide dismutase; CAT: catalase; GR: glutathione reductase; GPx: glutathione peroxidase; GST: glutathione S-transferase; GSSG: glutathione oxidized form; GSH: glutathione reduced form.

${ }^{*} P<0.05$.

The same tendency, although not statistically significant, was noted in GR activity. As expected, GSSG/GSH ratio was enhanced in CCM-treated rats. No changes were observed in the GST activity. For female rats, only SOD activity exhibited a decline and GSSG/GSH ratio showed an apparent increase, and the differences reached the level of statistical significance.

\section{Discussion}

It has been generally accepted that Cordyceps species have no critical toxicity for major organs [15]. Some commercial products are available in the market nowadays such as didanosine from C. militaris [16]. The nephrotoxicity characterized by necrotic tubules observed at $3 \mathrm{~g} / \mathrm{kg}$ group in our study was completely unexpected. Kidney changes were prominent in high-dose group (only males) and featured proteinaceous effusion in the glomerular capsule and multiple tubular lesions, including degeneration, necrosis, and dilation.

Nephrotoxicity is a major complication characterized by morphological destruction of intracellular organelles and cellular necrosis and followed by functional alterations including the depletion of the antioxidant defense system and mitochondrial damage [17]. Oxidative damage is thought to be one of the main mechanisms involved in nearly all chronic renal pathologies [18]. In order to explore this possibility, we assessed the activity of renal antioxidant 
enzymes SOD, GR, GPx, GST, and CAT. In detail, SOD and CAT are the main antioxidant enzymes in the body, which scavenge unwanted $\mathrm{O}_{2}, \mathrm{H}_{2} \mathrm{O}_{2}$, and $\mathrm{ROOH}$ produced by free radical. SOD catalyzes superoxide radical dismutation, and CAT further removed hydrogen peroxide. We observed a significant fall in the activities of kidneys SOD and CAT in the rats fed with CCM. GSH is an important nonenzymatic antioxidant system in kidney. It can act as a neutralizer of oxidant metabolites in a reaction catalyzed by the GST enzyme, or as a cofactor of several antioxidant enzymes as GR and GPx [19]. In the present study, the increment in GSSG/GSH ratio in kidneys was found after CCM treatment. The alteration in the activities of these enzymes, together with the alteration in the GSH/GSSG system, reflects that CCM can induce alterations to the oxidative system in the kidney. These differences may be related to the sex hormones which play an important role in acute kidney failure. For example, there is a gender difference with regard to the severity of hepatic oxidative stress in acute uremia, with female rats displaying significant protection relative to male rats [20]. Moreover, the toxicity of doxorubicin was much stronger in male rats; toxicity was diminished after castration, which is known to downregulate the expression of renal OAT1 in rats $[21,22]$. In the future, models such as orchidectomized males and ovariectomized females will be used to shed light on the role of hormone in the nephrotoxicity induced by $C$. militaris.

BUN and creatinine are considered as the traditional indicators of kidney damage; however, no change was observed in BUN and creatinine levels in our study. kIM-1 is a more sensitive biomarker which outperforms traditional biomarkers of kidney injury [23]. In our study, the low dose of CCM induced a minimal but significant increase in kIM-1 transcript levels in male rats, even in the absence of histopathological indications. kIM-1 gene expression increased significantly beginning at $1 \mathrm{~g} / \mathrm{kg}$ treatment of CCM, although the change appeared at the protein level only from $3 \mathrm{~g} / \mathrm{kg}$ treatment. Gene expression appeared to be more sensitive than either the kIM-1 protein level or urine assay. In the female rats, tubular damage induced by CCM at the high dose was less frequent and less severe, but it was captured by kIM-1 gene expression analysis. In accordance with the previous report [24], kIM-1 is expected to represent an important genomic marker for the potential screening of nephrotoxicants.

Cordycepin ( $3^{\prime}$-deoxyadenosine), a purine nucleoside derivative, is an active component of C. militaris. UPLC analysis showed that the content of cordycepin in C. militaris is $2.18 \mathrm{mg} / \mathrm{g}$ in our study. Sohn et al. reported that the epididymal weights of middle-aged rats were dose dependently increased by treatment with cordycepin. All cordycepintreated groups showed well-arranged spermatogonia, densely packed cellular material, and increased numbers of mature spermatozoa in the seminiferous lumen [25]. These may explain the increase in testis weight in the $2 \mathrm{~g} / \mathrm{kg}$ and $3 \mathrm{~g} / \mathrm{kg}$ groups in our study. Consistently, $C$. sinensis can enhance libido and sexual performance as well as ameliorates impaired reproductive functions such as impotency or infertility in males [26]. On the other hand, total cholesterol was lower in CCM-treated groups (both genders) than in the control group, and similar decrease was observed in C. guangdongensis-treated rats [15]. Interestingly, it is reported that C. sinensis extract decreased the serum cholesterol level of rats fed with a cholesterol-enriched diet [27, 28]. Cordycepin prevents hyperlipidemia in hamsters fed a high-fat diet via activation of AMP-activated protein kinase [29, 30]. Therefore, the change on testis weight and total cholesterol may be regarded as a positive effect.

\section{Conclusions}

For the first time, our results clearly indicate that CCM can induce nephrotoxicity to rats and male rats have greater sensitivity to nephrotoxicity than the female rats. Although the toxic dose level was relatively high, it is enough to arouse the public attention on the safety of herbal medicine. One of the oxidative stress markers such as GSSG/GSH ratio was increased due to CCM treatment. CCM also decreased the activity of antioxidant enzymes as well as promoted the protein and mRNA levels of KIM-1. Herein, we conclude that the mechanism may be explained, partially, by depleting the antioxidant defense system.

\section{Abbreviations}

$\begin{array}{ll}\text { AST: } & \text { Aspartate aminotransferase } \\ \text { ALT: } & \text { Alanine aminotransferase } \\ \text { BUN: } & \text { Blood urea nitrogen } \\ \text { CAT: } & \text { Catalase } \\ \text { CCM: } & \text { Cordyceps militaris } \\ \text { Cl: } & \text { Chloride } \\ \text { GPx: } & \text { Glutathione peroxidase } \\ \text { GR: } & \text { Glutathione reductase } \\ \text { GSSG: } & \text { Glutathione oxidized form } \\ \text { GSH: } & \text { Glutathione reduced form } \\ \text { GST: } & \text { Glutathione S-transferase } \\ \text { K: } & \text { Potassium; } \\ \text { KIM-1: } & \text { Kidney injury molecule-1 } \\ \text { Na: } & \text { Sodium } \\ \text { RBC: } & \text { Red blood cell count } \\ \text { SOD: } & \text { Superoxide dismutase } \\ \text { TC: } & \text { Total cholesterol } \\ \text { WBC: } & \text { White blood cell count. }\end{array}$

\section{Conflict of Interests}

The authors declare that there is no conflict of interests.

\section{References}

[1] X. Zhou, Z. Gong, Y. Su, J. Lin, and K. Tang, "Cordyceps fungi: natural products, pharmacological functions and developmental products," Journal of Pharmacy and Pharmacology, vol. 61, no. 3, pp. 279-291, 2009.

[2] J. S. Baik, H. Y. Kwon, K. S. Kim, Y. K. Jeong, Y. S. Cho, and Y. C. Lee, "Cordycepin induces apoptosis in human neuroblastoma SK-N-BE(2)-C and melanoma SK-MEL-2 cells," Indian Journal of Biochemistry \& Biophysics, vol. 49, no. 2, pp. 86-91, 2012. 
[3] E. S. Han, J. Y. Oh, and H. J. Park, "Cordyceps militaris extract suppresses dextran sodium sulfate-induced acute colitis in mice and production of inflammatory mediators from macrophages and mast cells," Journal of Ethnopharmacology, vol. 134, no. 3, pp. 703-710, 2011.

[4] J. W. Jeong, C. Y. Jin, C. Park et al., "Inhibition of migration and invasion of LNCaP human prostate carcinoma cells by cordycepin through inactivation of Akt," International Journal of Oncology, vol. 40, no. 5, pp. 1697-1704, 2012.

[5] B. Lin and S. Li, "Cordyceps as an herbal drug," in Herbal Medicine: Biomolecular and Clinical Aspects, I. F. F. Benzie and S. Wachtel-Galor, Eds., chapter 5, CRC Press, Boca Raton, Fla, USA, 2nd edition, 2011.

[6] K. Feng, Y. Q. Yang, and S. P. Li, "Renggongchongcao," in Pharmacological Activity-Based Quality Control of Chinese Herbs, S. P. Li and Y. T. Wang, Eds., pp. 155-178, Nova Science Publisher, New York, NY, USA, 2008.

[7] C. L. Cheng, K. J. Chen, P. H. Shih et al., "Chronic renal failure rats are highly sensitive to aristolochic acids, which are nephrotoxic and carcinogenic agents," Cancer Letters, vol. 232, no. 2, pp. 236-242, 2006.

[8] C. R. D. Colson and M. E. De Broe, "Kidney injury from alternative medicines," Advances in Chronic Kidney Disease, vol. 12, no. 3, pp. 261-275, 2005.

[9] F. D. Debelle, J. L. Vanherweghem, and J. L. Nortier, "Aristolochic acid nephropathy: a worldwide problem," Kidney International, vol. 74, no. 2, pp. 158-169, 2008.

[10] R. Scheuplein, G. Charnley, and M. Dourson, "Differential sensitivity of children and adults to chemical toxicity. I. Biological basis," Regulatory Toxicology and Pharmacology, vol. 35, no. 3, pp. 429-447, 2002.

[11] V. Linares, V. Alonso, M. L. Albina et al., "Lipid peroxidation and antioxidant status in kidney and liver of rats treated with sulfasalazine," Toxicology, vol. 256, no. 3, pp. 152-156, 2009.

[12] P. J. Hissin and R. Hilf, "A fluorometric method for determination of oxidized and reduced glutathione in tissues," Analytical Biochemistry, vol. 74, no. 1, pp. 214-226, 1976.

[13] D. Barrera, P. D. Maldonado, O. N. Medina-Campos, R. Hernández-Pando, M. E. Ibarra-Rubio, and J. PedrazaChaverri, "HO-1 induction attenuates renal damage and oxidative stress induced by $\mathrm{K}_{2} \mathrm{Cr}_{2} \mathrm{O}_{7}$," Free Radical Biology and Medicine, vol. 35, no. 1, pp. 1390-1398, 2003.

[14] J. Pedraza-Chaverri, P. Yam-Canul, Y. I. Chirino, D. J. SánchezGonzález, C. M. Martínez-Martínez, and C. Cruz, "Protective effects of garlic powder against potassium dichromate-induced oxidative stress and nephrotoxicity," Food and Chemical Toxicology, vol. 46, no. 2, pp. 619-627, 2008.

[15] W. J. Yan, T. H. Li, Q. Y. Lin, B. Song, and Z. D. Jiang, "Safety assessment of Cordyceps guangdongensis," Food and Chemical Toxicology, vol. 48, no. 11, pp. 3080-3084, 2010.

[16] R. R. M. Paterson, "Cordyceps-a traditional Chinese medicine and another fungal therapeutic biofactory?" Phytochemistry, vol. 69, no. 7, pp. 1469-1495, 2008.

[17] J. Joy and C. K. K. Nair, "Amelioration of cisplatin induced nephrotoxicity in Swiss albino mice by Rubia cordifolia extract," Journal of Cancer Research and Therapeutics, vol. 4, no. 3, pp. $111-115,2008$.

[18] K. Wojcikowski, L. Stevenson, D. Leach, H. Wohlmuth, and G. Gobe, "Antioxidant capacity of 55 medicinal herbs traditionally used to treat the urinary system: a comparison using a sequential three-solvent extraction process," Journal of Alternative and Complementary Medicine, vol. 13, no. 1, pp. 103-109, 2007.
[19] M. Romeu, M. Mulero, M. Giralt et al., "Parameters related to oxygen free radicals in erythrocytes, plasma and epidermis of the hairless rat," Life Sciences, vol. 71, no. 15, pp. 1739-1749, 2002.

[20] F. Golab, M. Kadkhodaee, J. Xu, and M. Soleimani, "Male susceptibility to hepatic damage in acute uremia in rats," Urology, vol. 78, no. 1, pp. 232.el-232.e6, 2011.

[21] M. Ljubojević, C. M. Herak-Kramberger, Y. Hagos et al., "Rat renal cortical OAT1 and OAT3 exhibit gender differences determined by both androgen stimulation and estrogen inhibition," American Journal of Physiology, vol. 287, no. 1, pp. F124-F138, 2004.

[22] T. Sakemi, N. Ohtsuka, Y. Tomiyoshi, and F. Morito, "Sex difference in progression of adriamycin-induced nephropathy in rats," American Journal of Nephrology, vol. 16, no. 6, pp. 540$547,1996$.

[23] T. Ichimura, C. C. Hung, S. A. Yang, J. L. Stevens, and J. V. Bonventre, "Kidney injury molecule-1: a tissue and urinary biomarker for nephrotoxicant-induced renal injury," American Journal of Physiology, vol. 286, no. 3, pp. F552-F563, 2004.

[24] E. T. Gatzidou, A. N. Zira, and S. E. Theocharis, "Toxicogenomics: a pivotal piece in the puzzle of toxicological research," Journal of Applied Toxicology, vol. 27, no. 4, pp. 302-309, 2007.

[25] S. H. Sohn, S. C. Lee, S. Y. Hwang et al., "Effect of longterm administration of cordycepin from Cordyceps militaris on testicular function in middle-aged rats," Planta Medica, vol. 78, no. 15 , pp. 1620-1625, 2012.

[26] J. S. Zhu, G. M. Halpern, and K. Jones, “The scientific rediscovery of an ancient Chinese herbal medicine: cordyceps sinensispart I," Journal of Alternative and Complementary Medicine, vol. 4, no. 3, pp. 289-303, 1998.

[27] J. H. Koh, J. M. Kim, U. J. Chang, and H. J. Suh, "Hypocholesterolemic effect of hot-water extract from mycelia of Cordyceps sinensis," Biological and Pharmaceutical Bulletin, vol. 26, no. 1, pp. 84-87, 2003.

[28] Y. J. Niu, R. Y. Tao, Q. Liu et al., "Improvement on lipid metabolic disorder by $3^{\prime}$-deoxyadenosine in high-fat-dietinduced fatty mice," American Journal of Chinese Medicine, vol. 38, no. 6, pp. 1065-1075, 2010.

[29] J. Gao, Z. Q. Lian, P. Zhu, and H. B. Zhu, "Lipid-lowering effect of cordycepin ( $3^{\prime}$-deoxyadenosine) from Cordyceps militaris on hyperlipidemic hamsters and rats," Acta Pharmaceutica Sinica, vol. 46, no. 6, pp. 669-676, 2011.

[30] P. Guo, Q. Kai, J. Gao et al., "Cordycepin prevents hyperlipidemia in hamsters fed a high-fat diet via activation of AMPactivated protein kinase," Journal of Pharmacological Sciences, vol. 113, no. 4, pp. 395-403, 2010. 


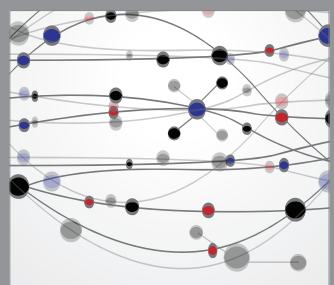

The Scientific World Journal
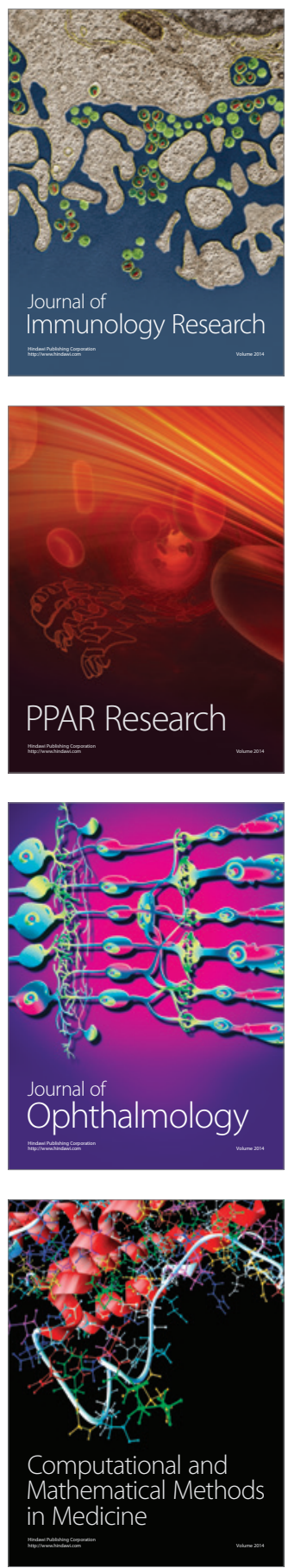

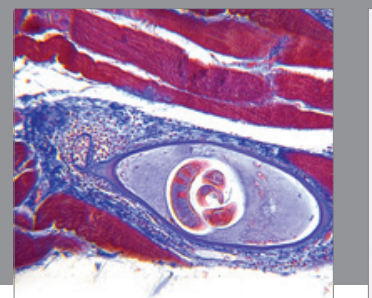

Gastroenterology

Research and Practice
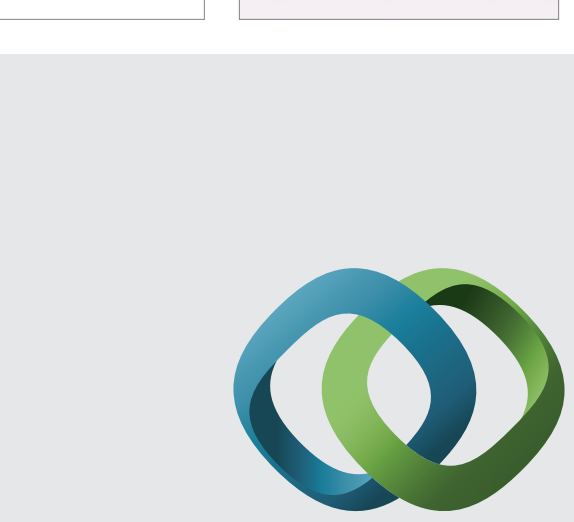

\section{Hindawi}

Submit your manuscripts at

http://www.hindawi.com
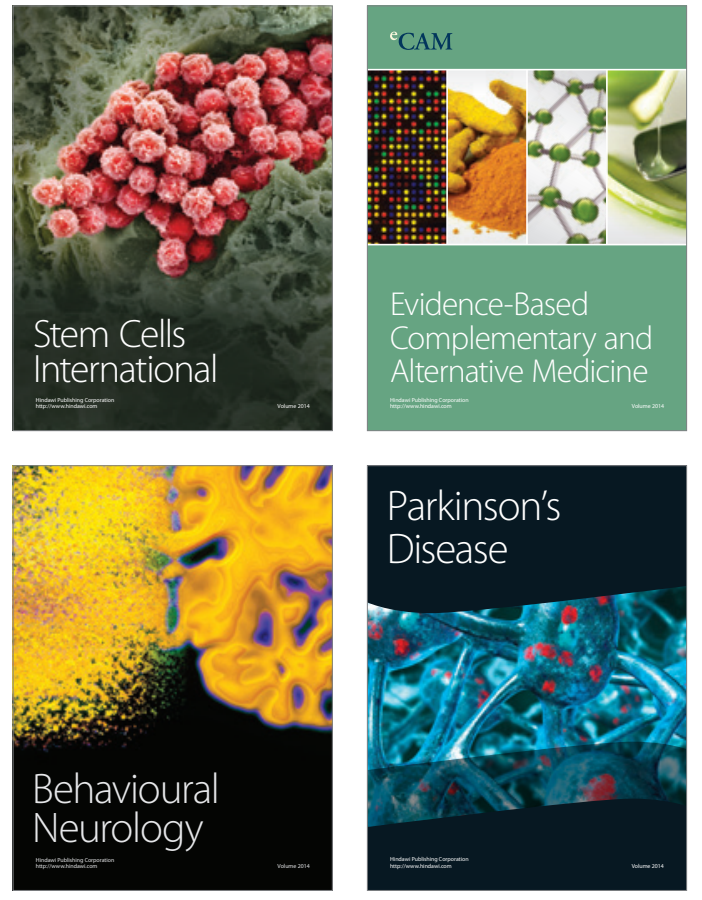
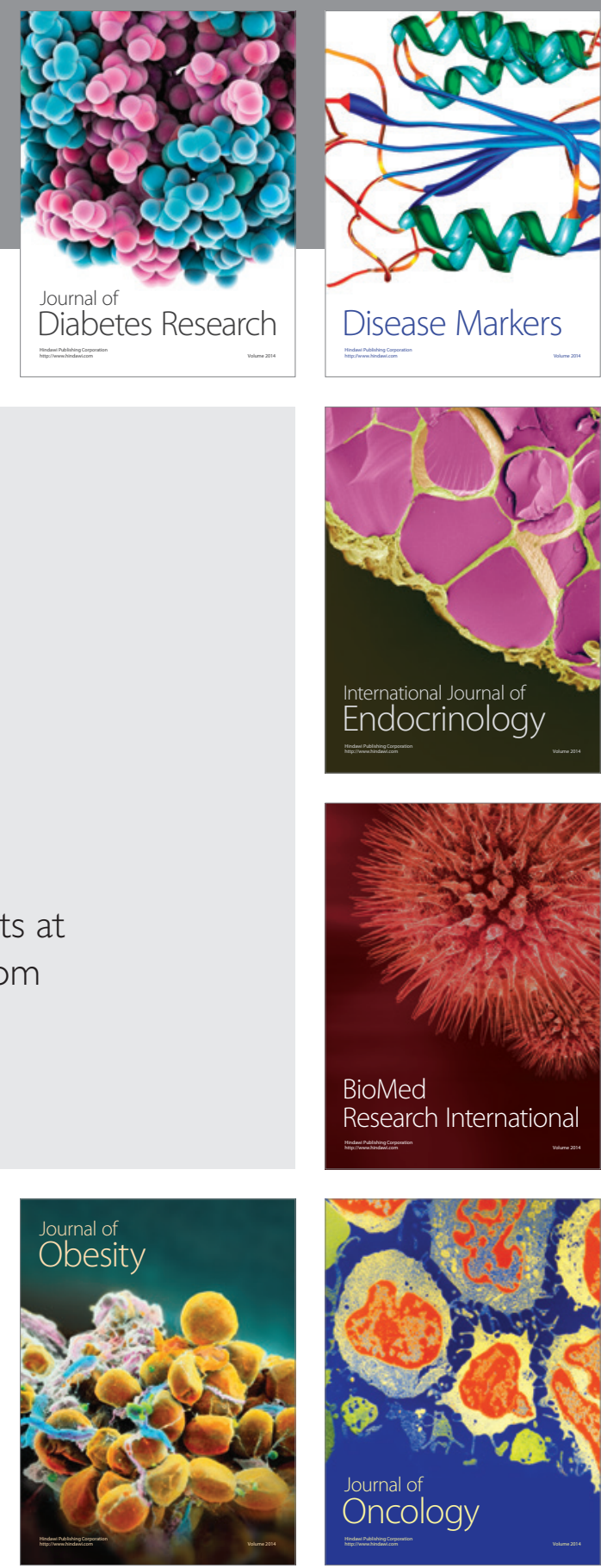

Disease Markers
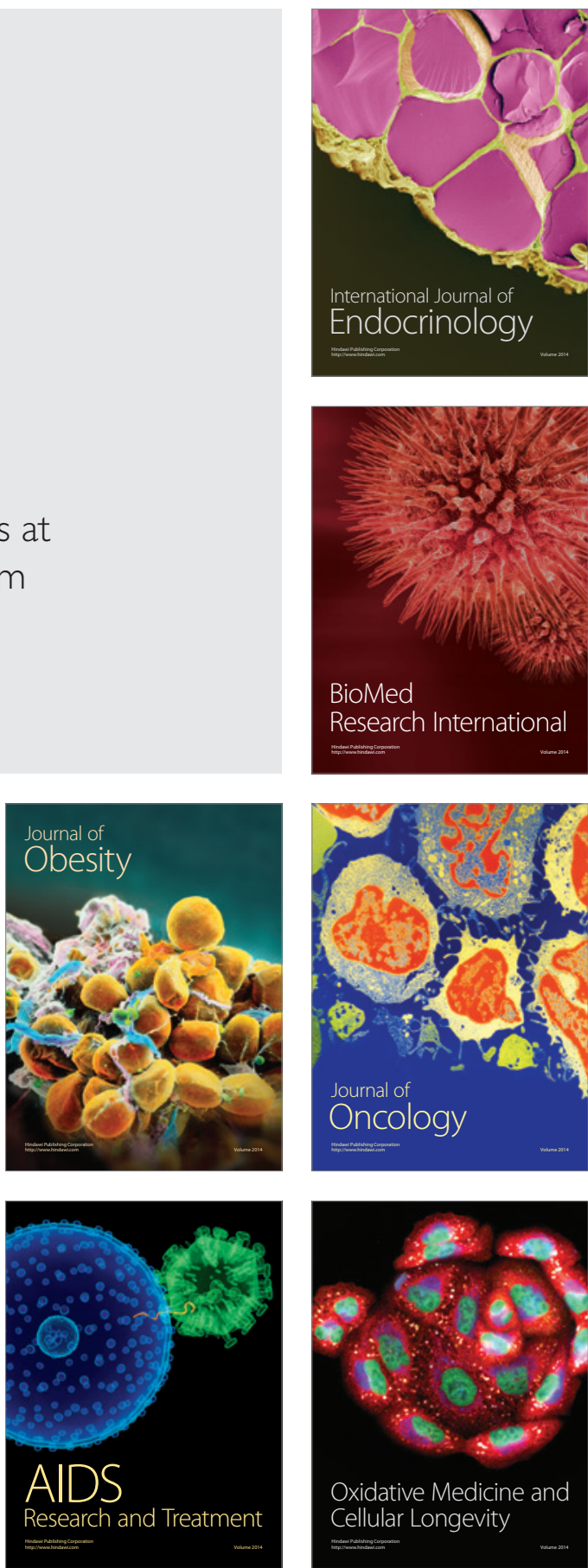